\title{
Immature, semi-mature, and fully mature dendritic cells: toward a DC-cancer cells interface that augments anticancer immunity
}

\author{
Aleksandra M. Dudek ${ }^{\dagger}$, Shaun Martin ${ }^{\dagger}$, Abhishek D. Garg * and Patrizia Agostinis*
}

Laboratory of Cell Death Research and Therapy, Department of Cellular and Molecular Medicine, KU Leuven, Leuven, Belgium

\section{Edited by:}

Kristian Michael Hargadon, Hampden-Sydney College, USA

Reviewed by:

Nadege Bercovici, Centre national de la recherche scientifique, France

Carlos Alfaro, Clínica Universidad de Navarra, Spain

\section{*Correspondence:}

Abhishek D. Garg and Patrizia

Agostinis, Laboratory of Cell Death

Research and Therapy, Department of

Cellular and Molecular Medicine, KU

Leuven, Campus Gasthuisberg

O\&N1, Herestraat 49, Box 802,

Leuven B-3000, Belgium

e-mail: abhishek.garg@

med.kuleuven.be;

patricia.agostinis@med.kuleuven.be

${ }^{\dagger}$ Aleksandra M. Dudek and Shaun Martin have contributed equally to this work.
Dendritic cells (DCs) are the sentinel antigen-presenting cells of the immune system; such that their productive interface with the dying cancer cells is crucial for proper communication of the "non-self" status of cancer cells to the adaptive immune system. Efficiency and the ultimate success of such a communication hinges upon the maturation status of the DCs, attained following their interaction with cancer cells. Immature DCs facilitate tolerance toward cancer cells (observed for many apoptotic inducers) while fully mature DCs can strongly promote anticancer immunity if they secrete the correct combinations of cytokines [observed when DCs interact with cancer cells undergoing immunogenic cell death (ICD)]. However, an intermediate population of DC maturation, called semi-mature DCs exists, which can potentiate either tolerogenicity or pro-tumorigenic responses (as happens in the case of certain chemotherapeutics and agents exerting ambivalent immune reactions). Specific combinations of DC phenotypic markers, DC-derived cytokines/chemokines, dying cancer cell-derived danger signals, and other less characterized entities (e.g., exosomes) can define the nature and evolution of the DC maturation state. In the present review, we discuss these different maturation states of DCs, how they might be attained and which anticancer agents or cell death modalities (e.g., tolerogenic cell death vs. ICD) may regulate these states.

Keywords: immunogenic cell death, phenotypic DC maturation, cytokine, antigen, cell death, cancer, immunosurveillance, chemotherapy

\section{INTRODUCTION}

It is conceptually established that the immune system can be distributed across two basic components, i.e., the innate immune system and the adaptive immune system $(1,2)$. The primary aim of innate immune cells is to provide a rapid non-specific response to any pathogen or foreign aggressors (possessing foreign antigens), wound, inflammatory insult, or newly initiated diseased cell (owning possible "non-self" antigens) $(1,2)$. On the other hand, the primary aim of adaptive immune cells is to provide a latent but highly specific response against foreign or "non-self" antigens and to generate an "immune memory" against these antigens to counter similar insults in the future more quickly (either

Abbreviations: $\mathrm{APC}(\mathrm{s})$, antigen-presenting cell(s); CD, cluster of differentiation; DAMPs, damage-associated molecular patterns; DC(s), dendritic cell(s); DEX(s), dendritic cell-derived exosomes; ER, endoplasmic reticulum; GM-CSF, granulocyte macrophage colony stimulating factor; Hyp-PDT, hypericin-based photodynamic therapy; ICD, immunogenic cell death; iDC(s), immature dendritic cell(s); IFN, interferon; IKDCs, IFN-producing dendritic cells; IL, interleukin; imDEXs, immature dendritic cells derived exosome(s); LFA-1, leukocyte function-associated antigen-1; mDEXs, mature dendritic cells derived exosome(s); MDSC, myeloid derived suppressor cells; NK, natural killer cells; NKDCs, natural killer dendritic cells; NLRs, NOD-like receptors; PAMPs, pathogen-associated molecular pattern(s); PRRs, pattern recognition receptors; TAA(s), tumor-associated antigen(s); $\operatorname{TDE}(\mathrm{s})$, tumor derived exosome(s); TGF, transforming growth factor; TIDCs, tumor-infiltrating dendritic cells; TLRs, toll-like receptors; TNF, tumor necrosis factor. cell interaction dependent or independent; the latter applying to antibody production) $(3,4)$. Together these two branches of the immune system are supposed to initiate acute inflammation ultimately culminating in its resolution and wound healing once they have taken care of the aggressor, insult, or diseased cell $(5,6)$. It is noteworthy that in terms of evolution, the conception of the innate immune system pre-dates that of the adaptive immune system (1). Most notable innate immune cells include macrophages, natural killer (NK) cells, dendritic cells (DCs), various myeloid lineage subsets, neutrophils, basophils, and eosinophils $(1,6)$; while the most notable adaptive immune cells include $\mathrm{T}$ and $\mathrm{B}$ lymphocytes $(3,5)$.

The initial reaction orchestrated by innate immune cells consists of capturing, as well as clearing up or destroying the source of injury, infection, or diseased cells, followed by wound healing and if required (in case of well discernable antigens) "priming" of the adaptive immune cells against antigens derived from the "nonself" diseased cells or pathogens $(1,2)$. This adaptive immune cell priming helps to initiate more specific responses, directed against the acquired antigens and leading to the eradication of the antigen source $(3,6)$. This in principle is also the basic theory behind anticancer immunity or anticancer immunosurveillance (7), where innate immune cells recognize the "non-self" tumor-associated antigens (TAAs) and prime adaptive immune cells (mainly T cells) against them. This leads to both: direct and indirect cancer killing, 
anticancer effector functions, production of anti-TAA antibodies and subsequent immunity capable of rejecting tumor cells possessing the corresponding TAAs $(3,8)$. In this complex interplay, one may appreciate that the step of "priming" adaptive immune cells by innate immune cells against TAAs represents a crucial milestone that is completely dependent on the antigen-presenting and antigen-sensing capabilities of innate immune cells (2). While most innate immune cells (professional presenters) and certain cells of epithelial lineage (non-professional presenters) are capable of presenting antigens to the adaptive immune cells (6) be it to varying degrees; yet the sentinel antigen-presenting cells (APCs) of the immune system are the DCs $(2,3,9)$. DCs are the guardian APCs because they are both efficient at antigen-presenting and adaptive immune cell activation and also good at judging whether an entity possesses "self" or "non-self" antigens $(2,10,11)$. The ability of DCs to present "non-self" TAAs properly to prime as well as to activate adaptive immune cells is an absolute pre-requisite for activation of potent anticancer immunity $(2,4)$.

In the present review we briefly discuss the basic biology of DC activation states that can make a difference between protumorigenic inflammation and anti-tumorigenic immunity. We will then discuss in more detail the ability of anticancer therapeutics to influence and modulate these activation states and the crucial impact of exosomal communication on DC-associated functions.

\section{DENDRITIC CELLS AND THEIR ACTIVATION STATES: A BIRD'S EYE-VIEW}

The molecular cell biology of DCs has evolved in a sophisticated manner to facilitate its APC functions (12). DCs in general possess a diverse repertoire of surface receptors (and intracellular receptors) that help them in environmental sensing and to carry out "at will" rapid innate immunity-related functions $(2,12)$. Such receptors include various scavenging or phagocytic receptors like CD91, integrins, CD36 (aiding in phagocytosis and clearance of target entities), surface pattern recognition receptors (PRRs) like toll-like receptors (TLRs), and intracellular PRRs like NOD-like receptors (NLRs) $(10,13,14)$. DC-based PRRs help in detection (and subsequent DC stimulation) of danger signals like pathogen-associated molecular patterns (PAMPs) or damage-associated molecular patterns (DAMPs) $(4,5,8)$.

Dendritic cells are also special in terms of their antigen processing machinery. Classically (for non-professional APCs and normal cells, as applicable), antigens derived from intracellular sources are presented by the major histocompatibility complex (MHC) class I presentation system while extracellular antigens (captured via phagocytosis or pinocytosis) are preferentially processed for MHC class II presentation (15). In specialized APCs like DCs however, the extracellular antigens can also gain access to the MHC class I presentation system (mediated by following events: phagophore $\rightarrow$ endosome $\rightarrow$ antigen escape from endosome $\rightarrow$ antigen processing by cytosolic proteasome for MHC I presentation) while intracellular antigen fragments can also be found on the MHC class II molecules (mediated by autophagy) a phenomenon termed as "cross-presentation" (15). This unique ability to cross-present antigens to adaptive immune cells is also behind DCs' significant role as APCs. Depending on the environment they encounter (e.g., normal "self" antigen rich environment or abnormal "non-self" antigen rich environment); DCs can exhibit various states and accordingly perform different functions $(2,12)$. Based on a highly stark difference between antigenic environments, i.e., host "self" antigens vs. foreign or pathogenassociated "non-self" antigens, DCs can exist in two main states, i.e., steady state immature dendritic cells (iDCs) and fully mature DCs $(9,12)$. The distinction between immature and mature DCs is partly based on changes occurring on two crucial levels, i.e., phenotypic level and functional level $(2,14,16)$. Phenotypic maturation is attained when DCs up-regulate surface maturation ligands such as CD80, CD83, and CD86 along with the MHC class II molecule (9). DCs stimulated on the functional level exhibit the ability to secrete cytokines where the balance between inflammatory or immunostimulatory cytokines (e.g., IL-12, IL-6, IL-1 $\beta$ ) and immunosuppressive cytokines (e.g., IL-10, TGF- $\beta$ ) is decided by the "environmental context" $(2,9,17)$.

In normal, healthy conditions, DCs exist in an immature or steady state such that in this scenario their main aim is to maintain immune tolerance by impeding adaptive immune cells from attacking host cells that possess "self" antigens $(4,10,12)$. However, if DCs encounter "non-self" entities in the periphery, they opsonize them, process their antigens for cross-presentation, migrate to the lymph nodes, and prime naïve $\mathrm{T}$ cells for these antigen (9). DCs provide the $\mathrm{T}$ cells with the information about whether an antigen is present and whether it poses a threat - a foundational mechanism for the subsequent $\mathrm{T}$ cell effector function (18). A single DC can contact as many as $\sim 5000 \mathrm{~T}$ cells per hour (19). Steady state iDCs exhibit continuous endocytic activity (20) and hence continuously present "self" antigens to T cells. However in this case the $\mathrm{T}$ cells are not polarized toward an effector state but are rather polarized to facilitate tolerance or immunosuppression $(12,21)$. Such immunotolerance is actively induced and maintained through a mixture of immune checkpoint pathways and complete lack of stimulatory signals provided by the DCs (22). Immune checkpoint pathways are a plethora of inhibitory cascades that are crucial for maintaining self-tolerance and modulation of duration/amplitude of immune response, e.g., DC-based presentation of ligands like cytotoxic T-lymphocyteassociated antigen 4 (CTLA4) and programed cell death protein 1 (PD1) to $\mathrm{T}$ cells causing $\mathrm{T}$ cell anergy or differentiation of immunosuppressive $\mathrm{T}$ cells (22). Such immunosuppressive $\mathrm{T}$ cells (e.g., regulatory $\mathrm{T}$ cells, $\mathrm{T}_{\text {regs }}$ ) further help in spreading tolerance toward "self-antigens" $(6,9)$. On the other hand, when DCs encounter pathogens or entities possessing PAMPs (detected in part through PRRs) they switch to a mature state exhibiting strong phenotypic and functional stimulation. At this stage, the DCs leave the function of phagocytic scavenging and assume the more sophisticated APC-function (12). Subsequently, DCs carefully co-ordinate their proteolytic processes in the cytosol (e.g., proteasomes), endosomes-lysosomes (e.g., lysosomal hydrolases), and the endoplasmic reticulum (ER) to degrade "non-self" entityderived proteins in order to yield suitable antigenic peptides that are subsequently loaded on MHC class I and II molecules for presentation to $\mathrm{T}$ and $\mathrm{B}$ cells $(9,12)$. The simultaneous presence of phenotypic maturation ligands, suitable cytokines, other functional immunostimulatory factors, and appropriate antigen-MHC 
complexes helps activate an effector profile in interacting $\mathrm{T}$ cells thereby polarizing them for antigen-specific elimination of the "non-self" entity (9). Here, antigen-MHC complexes are the main stimulatory signals (signal 1 , detected by the $\mathrm{T}$ cells through a complex of T-cell receptors/TCRs-CD3) followed by phenotypic maturation ligands. These ligands help in providing proper costimulation by binding corresponding receptors on $\mathrm{T}$ cells (signal 2, detected by T cell receptors like CD28, CD40L) in the presence of cytokines or factors eliciting immunostimulation and the effector T cell phenotype (signal 3, detected by respective cytokine cognate receptors) (9). The presence of these three signals is absolutely essential for effective T cell stimulation by APCs (like DCs) and their polarization toward anti-pathogenic effector function (6, 9). It is noteworthy though, that apart from these three signals, DCs might modulate $T$ cell function via other immunomodulatory signals (e.g., exosomes, discussed later); however because they still lack a well-characterized functional status, they cannot yet be ascribed as bona fide $\mathrm{T}$ cell modulatory signals. Last but not least, it is important to consider that maturation of DCs is primarily crucial for the activation and differentiation of naïve T cells (10). Pre-existing cytotoxic $\mathrm{T}$ cells and memory $\mathrm{T}$ cell populations are not very strongly dependent on fully mature DCs for their effector functions $(2,3,12)$.

\section{TUMOR-INFILTRATING DCs: AN OVERVIEW}

The Dichotomy of DC maturation states is mainly applicable to an environment where a very obvious distinction exists between "self" and "non-self" antigens. The continuum of DC activation states is much more complex when it comes to cancer as most cancerous tissues or tumors are very similar in terms of antigenic make-up to that of normal cells $(5,12)$. This is attributable to the fact that most antigens are either shared with nearby normal tissues (e.g., differentiation antigens) or with spatiotemporally distinct yet normal tissue [e.g., oncofetal antigens or cancer-testis antigens (7)]. This leads to a strong conflict regarding what represents "self" or "non-self" - which is further revived by the struggle between the tolerance-encouraging tendency of DCs and their propensity to prime $\mathrm{T}$ cells for tumor rejection $(4,9,12)$. This situation is further exacerbated by the capacity of cancer cells to interfere with normal DC function (23) via immunosuppressive cytokines or other signals like those conveyed by exosomes (discussed later).

In a well-established tumor, cancer cells actively suppress steady state DCs (also called tumor-infiltrating DCs or tumor-infiltrating dendritic cell, TIDCs) and keep them in the favorable immature state (Figure 1) (23-25). Such immature TIDCs tend to exhibit dysfunction in antigen-presenting capabilities, suppressed endocytic activity, abnormal motility, and various other immature characteristics - a point that has been demonstrated in a number of studies analyzing various solid tumors and tumor-draining lymph nodes (26). Such induction of immature state in TIDCs by the tumor is not surprising considering that mature DC's density in tumors inversely correlates with tumor pathologic grade/stage and positively correlates with improved prognosis (26). Moreover, tumors may also actively induce apoptosis in TIDCs through certain gangliosides (e.g., GM3, GD3), glycoproteins (e.g., MUC2 mucins), and neuropeptides $(25,26)$.
The tumor-induced iDCs state is mainly characterized by: (1) the total absence or presence of negligible amounts of well-processed cancer antigens (compromised signal 1 generation), (2) absence or trivial amounts of phenotypic maturation ligands or co-stimulatory molecules (ablation of signal 2), and (3) either complete absence or minor presence of functional stimulus/immunostimulatory cytokines like IL-12 (ablated signal 3) (7, $10,12,23)$. Such iDCs can also be encouraged by the presence of non-immunogenic cancer cell death [e.g., tolerogenic apoptosis $(11)](5,21,27,28)$. The presence of signal 1, i.e., processed cancer antigens is very crucial for potent elicitation of anti-tumor immunity since signals $2 / 3$ have less meaning in absence of signal 1 (18). Thus not surprisingly, one of the immunoevasive strategies employed by cancer cells is the down-regulation or loss of antigens $(7,21)$. DCs prime the T cells for cancer antigens in the lymph nodes in three phases $(18,29)$; Phase I lasts for $\sim 8 \mathrm{~h}$ and consists of transient interactions between $\mathrm{T}$ cells and antigen-presenting DCs (29). T cells integrate antigenic stimulus from several such Phase I encounters until the cumulative signal triggers the onset of Phase II. During Phase II (which lasts $\sim 12 \mathrm{~h}$ ), T cells form a long-lasting stable contact with a single DC (29). It is noteworthy that this Phase I-II transition depends strongly on the concentration of antigenic peptide-MHC complex per DC $(18,30)$; higher the concentration, the faster the tendency of T cells to exit Phase I and reach Phase II (18). Thus, lower cancer cell-associated antigen levels make it harder for the $\mathrm{T}$ cells to exit Phase I - a scenario that leads to unstable DC-T cell interactions and compromised $\mathrm{T}$ cell immunity. Phase II is also the stage where T cells are further activated via DC-based signals 2 and 3 (29). Thereafter, the T cells enter Phase III during which they proliferate vigorously and return to short interactions with the DCs (29). It should be note however, that the above "three phase theory" of DC-T cell interactions is mainly based on in vitro/ex vivo studies using either model antigens or high concentrations of TAA-based immunodominant peptides. Such studies need to be extended to settings of DC-T cell interactions within a tumor-bearing host, in near future.

Apart from antigen down-regulation, cancer cells also directly induce an immature TIDC state through secretion of immunosuppressive factors like IL-10, VEGF, TGF- $\beta$, and PGE $2(7,25,27)$; thereby further compromising stable DC-T cell interactions. The strategies and mechanisms employed by cancer cells for inducing DC-based tolerogenicity have been discussed in details in certain recent reviews $(5-7,21)$. Curiously it has been demonstrated recurrently that in an ex vivo set-up, certain iDCs may exhibit the ability to directly lyse transformed cells or tumor cells in vitro (31). Such iDCs have been termed as natural killer dendritic cells (NKDCs) or more recently interferon-producing killer DCs (IKDCs) (Figure 1) (31) and have been found to exert anticancer cytotoxic activity in vitro in both rodent and human set-ups (31-33). While, IKDCs may simply reflect the prevalent ex vivo DC heterogeneity yet their characterization raises the need to better study DC features in tumor-bearing hosts.

\section{ACTIVATION STATES IN TUMOR IMMUNOSURVEILLANCE AND ANTI-TUMOR IMMUNITY}

As per the theory of cancer immunoediting, during tumor development the equilibrium between growing tumor and immune 


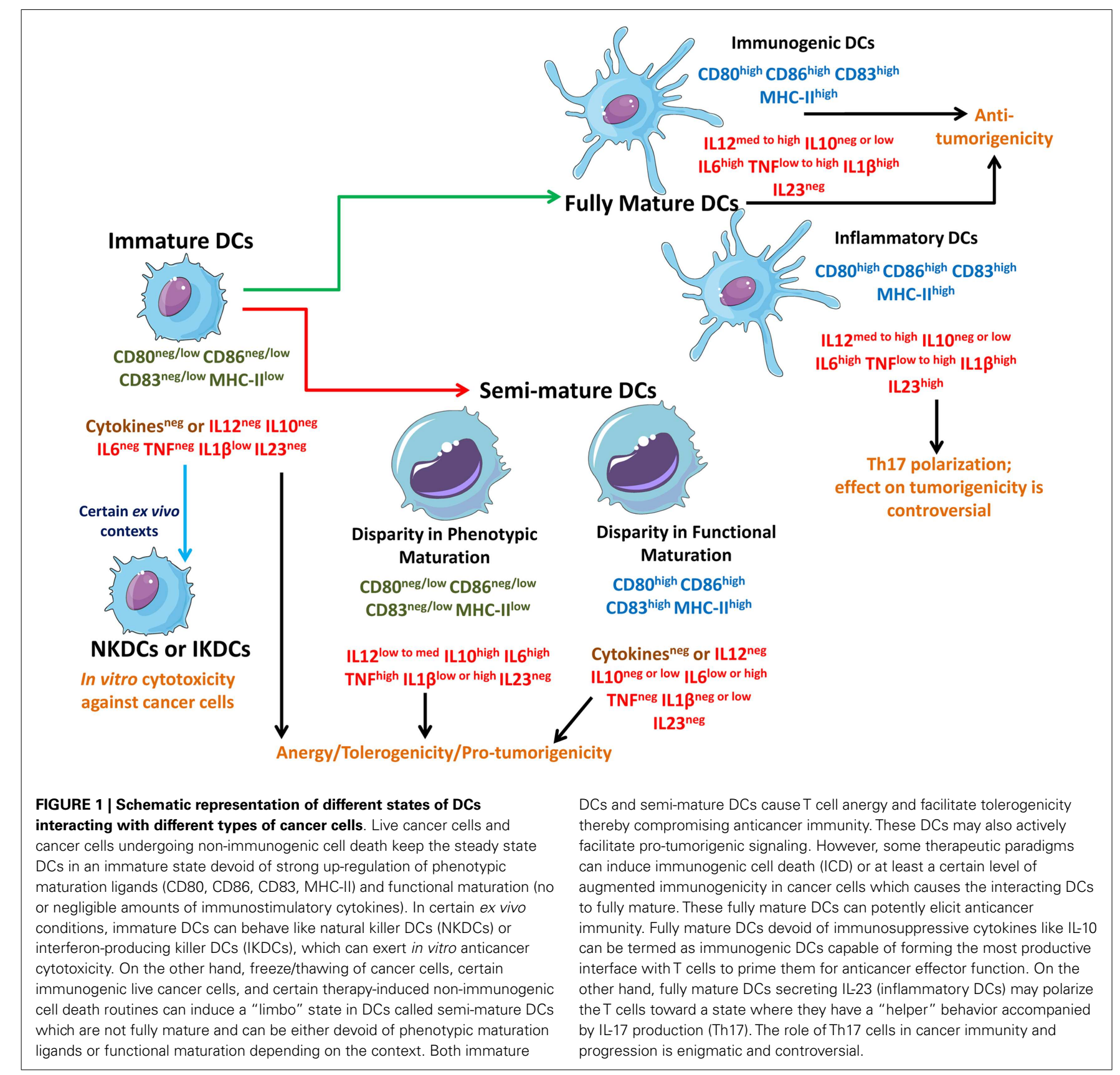

system shifts: at the beginning the immune system is capable of recognizing and exterminating cancer cells ("elimination" phase). Later, cancer "immunoediting" and release of cancerderived immunosuppressive factors, results in the establishment of an equilibrium between cancer cells that are still susceptible to immunoeradication and immunoevasive ones that are resistant to anticancer immunity ("equilibrium" phase). Finally, as the immune evasion process progresses, the tumor escapes immune cell control ("escape" phase) (34). It has been long proposed that anticancer therapies should kill the cancer cells in a manner that helps activate the DCs to prime the adaptive immune system for anticancer activity $(28,35)$, however the experimental as well as clinical translation of this idea have unfortunately not been straightforward. This may result from the fact that most anticancer therapies tend to induce either non-immunogenic or very low-immunogenic cancer cell death (11) and thereby disallowing sufficient DC stimulation $(5,21,27,35)$ and keeps the DCs in an immature state (Figure 1). For instance, certain therapeutic modalities (e.g., chemotherapeutics like cisplatin) or certain anti-tumor vaccine-preparation methodologies (i.e., freeze/thawing, discussed later in Anticancer Therapy Differently Shapes the DC-Dying Cancer Cells Interface), may actually cause a sub-optimal activation of DCs $(24,28,36,37)$ thereby giving rise to a somewhat "limbo" state which can be termed as "semi-mature" 
Table 1 | Inducers of cancer cell death that stimulates full maturation of DCs.

\begin{tabular}{|c|c|c|c|c|c|c|}
\hline $\begin{array}{l}\text { Anticancer } \\
\text { therapy }\end{array}$ & $\begin{array}{l}\text { In vitro } \\
\text { Phagocytosis }\end{array}$ & $\begin{array}{l}\text { Phenotypic } \\
\text { maturation of DCs }\end{array}$ & $\begin{array}{l}\text { Release of } \\
\text { cytokines by DCs }\end{array}$ & $\begin{array}{l}\text { Stimulation of } \\
\mathrm{T} \text { cells }\end{array}$ & $\begin{array}{l}\text { In vivo mice } \\
\text { experiments }\end{array}$ & Clinical data \\
\hline Hypericin-PDT & Garg et al. (37) & Garg et al. (37) & $\begin{array}{l}\text { IL-1 } \beta \text { (37); IL-6 (50); } \\
\text { NO (37); IL-12p70 } \\
\text { (Dudek et al., } \\
\text { unpublished data) }\end{array}$ & $\begin{array}{l}\text { Proliferation (50) } \\
\text { IFN } \gamma \text { release (50) }\end{array}$ & $\begin{array}{l}\text { In vitro-treated cancer } \\
\text { cells induce antitumor } \\
\text { immunity in mice } \\
\text { vaccination experiment } \\
\text { (37) }\end{array}$ & \\
\hline $\begin{array}{l}\text { Cyclophospha } \\
\text { mide (MAFO } \\
\text { for in vitro } \\
\text { experiments) }\end{array}$ & & $\begin{array}{l}\text { Kotera et al. (52), } \\
\text { Schiavoni et al. (53) }\end{array}$ & $\begin{array}{l}\text { IL-1 } \beta, \text { IL-6, IL-12 (52, } \\
53)\end{array}$ & & & $\begin{array}{l}\text { Increased infiltration of } \\
\text { phenotypically mature DCs } \\
(53,55-57) \text {; increased DCs } \\
\text { trafficking to the lymph } \\
\text { node (53) }\end{array}$ \\
\hline$\gamma$ Irradiation & $\begin{array}{l}\text { Prasad et al. } \\
\text { (58), Kim et al. } \\
\text { (59) }\end{array}$ & $\begin{array}{l}\text { Prasad et al. (58), } \\
\text { Kim et al. (59) }\end{array}$ & IL-6 (59) & IFN $\gamma$ release (62) & $\begin{array}{l}\text { After tumor irradiation: } \\
\text { (1) increase in } \\
\text { tumor-infiltrating mature } \\
\text { DCs }(60,61) \text {; (2) } \\
\text { increase in IFN } \gamma \\
\text { production by spleen } \\
\text { cells (63) }\end{array}$ & \\
\hline Doxorubicin & $\begin{array}{l}\text { Obeid et al. } \\
(132)\end{array}$ & $\begin{array}{l}\text { Ghiringhelli et al. } \\
\text { (134) }\end{array}$ & IL-1 $\beta$ (134) & $\begin{array}{l}\text { Proliferation and } \\
\text { IFN } \gamma \text { release (133) }\end{array}$ & & \\
\hline $\begin{array}{l}\text { CMO and } \\
\text { colchicines }\end{array}$ & & Wen et al. (137) & & Proliferation (137) & & \\
\hline $\begin{array}{l}\text { Oncolytic } \\
\text { viruses }\end{array}$ & & $\begin{array}{l}\text { Moehler et al. (73), } \\
\text { Donnelly et al. } \\
\text { (138) }\end{array}$ & & $\begin{array}{l}\text { Release of IFN } \gamma \\
\text { (138), release of } \\
\text { TNF and IL-6 (73) }\end{array}$ & & \\
\hline
\end{tabular}

DCs (Figure 1) (10). It is noteworthy though that in certain instances, semi-mature DCs generated ex vivo and injected back into the host (in this case rhesus macaque) might become mature spontaneously during migration before reaching the lymph nodes (38). However, whether this situation applies to therapeutic DC vaccines is an enigmatic question since the above mentioned study was not done within the context of anticancer DC vaccines. In various anticancer therapy settings (see Table 1 and Anticancer Therapy Differently Shapes the DC-Dying Cancer Cells Interface), DCs interacting with dead/dying cancer cells (treated with nonimmunogenic or low-immunogenic anticancer agents) may attain a semi-mature state, i.e., while they may present low/medium levels of cancer antigens yet they either lack co-stimulatory signals (e.g., CD86) or suitable immunostimulatory cytokines (e.g., IL-12) $(6,10,28,37)$. Thus, semi-mature DCs, unlike iDCs, exhibit the ability to sustain at least two (i.e., signal 1 and either one of the other two signals) of the three signals required for successful/optimal $\mathrm{T}$ cell activation (23) but unfortunately not all three at once and thereby they exhibit an unstable interface with $\mathrm{T}$ cells that leads to active ablation of anticancer immunity (10) and clonal T cell anergy $(20,23,24)$. Semi-mature DCs might exhibit inconsistency in either up-regulation of phenotypic maturation ligands or in secretion of cytokines (Figure 1). Semi-mature DCs with disparity in phenotypic maturation are able to secrete 
one or more of the few assorted cytokines like IL-10, IL-6, IL-1 $\beta$, and tumor necrosis factor (TNF), but do so to a highly variable degree (in terms of amount and simultaneous presence of these cytokines together) $(23,28,37)$. It is also noteworthy that certain well-established tumors composed of immunogenic cancer cells (e.g., melanoma) may also encourage formation of de novo semi-mature TIDCs rather than immature TIDCs due to the particular tumor microenvironment they can create (39). Together iDCs and semi-mature DCs tend to encourage T cell anergy or T cell exhaustion $(9,10)$, tolerogenicity toward the cancer cell (9, 31 ), and even active pro-tumorigenic activity (e.g., semi-mature DC-derived IL-6 may act as a growth factor for tumors expressing IL-6R-gp130 cognate receptors and/or IL-10 can act as a general immunosuppressor) $(17,40,41)$.

Recently however, it was described that certain therapeutic modalities [e.g., mitoxantrone/doxorubicin, hypericin-based photodynamic therapy (Hyp-PDT), and radiotherapy] cause cancer cells to undergo immunogenic cell death (ICD) $(28,35,40,42)$. ICD tends to be highly immunostimulatory because it emits a spatiotemporally defined combination of potent DAMPs that act as danger signals important for DCs stimulation (35). DCs detect such danger signals through a combination of receptors including TLRs, CD91, and purinergic receptors $(21,35)$. ICD may also ablate the canonical strategies harnessed by cancer cells to encourage the formation of immature or semi-mature DC states $(21,27)$. Beyond ICD, some anticancer therapeutics (e.g., antimitotic chemotherapeutics like docetaxel) may induce a general augmentation of immunogenicity that is not as strong as ICD but is still effective in a context-dependent fashion (43). Cancer cells undergoing ICD, or exhibiting therapy-induced (minor to medium increase of) immunogenicity, encourage the formation of fully mature DCs (Figure 1) $(10,27,28,35,37,43)$. In general, fully mature DCs exhibit all three conventional $\mathrm{T}$ cell stimulatory signals, thereby enabling elicitation of potent anticancer immunity $(12,13,31)$. However, based on the pattern of only a few cytokines fully mature DCs might be subdivided, i.e., immunogenic DCs and inflammatory DCs (Figure 1) $(35,44)$. The fully mature immunogenic DCs are supposed to exhibit the least or total absence of immunosuppressive cytokines like IL-10 $(17,21,40)$. Most known ICD inducers result in the formation of general fully mature DCs, with a context-dependent absence or reduced abundance of immunosuppressive cytokines (e.g., IL10) $(28,37,45)$. On the other hand, the presence of high IL-23 cytokine expression might be a marker of inflammatory DCs (44). Indeed, IL-23 may encourage T cells to exhibit the Th17 polarization ( $\mathrm{T}$ helper cells/Th cells producing IL-17 cytokine) (44). It is noteworthy that the role of inflammatory DC-Th17 arc in cancer progression is still enigmatic with evidence supporting both anti-tumorigenic and pro-tumorigenic roles for this interaction, depending on the context $(44,46,47)$. Thus for anticancer immunity, the functional role of fully mature inflammatory DCs needs to be treated with caution until further research ascertains their exact behavior.

It is noteworthy though, that the distinctions between different DC maturation or activation states made on the basis of phenotypic maturation markers or cytokine patterns are primarily based on ex vivo or in vitro experiments. This is because simultaneous analysis of various surface-associated and soluble DC activation markers is relatively easy ex vivo or in vitro. However, in vivo or in situ, such a simultaneous detection is nearly impossible. In vivo or in situ, mostly only the phenotypic maturation status of tumor-infiltrating DCs is detected via immunofluorescence staining (e.g., CD11b ${ }^{+}$CD $11 c^{+}$CD $86^{\text {high }}$ MHC-II ${ }^{\text {high }}$ DCs). While an analysis of cytokines associated with the tumor is possible via RT-PCR, proteomics-approaches, or antibody arrays, yet there is no way of characterizing which cytokines are secreted exclusively by the TIDCs. In future, lineage-tracing of the DCs in tumors or high enumeration staining/detection strategies for TIDCs might make it possible to simultaneously detect the phenotypic and functional markers of DCs in vivo or in situ however until that point, the above mentioned distinctions can be treated as operational definitions. Furthermore, it would be necessary to further characterize the additional states of semi-mature or fully mature DCs relevant for cancer treatment, not only in vitro/ex vivo but also in vivo/in situ.

\section{ANTICANCER THERAPY DIFFERENTLY SHAPES THE DC-DYING CANCER CELLS INTERFACE}

Anticancer therapies are capable of modulating DC states, either directly or via dying cancer cells. We believe that efficient anticancer treatment should be able to re-establish the recognition of cancer cells by the immune system, as well as "revive" the dominance of the immune system in this cross-talk. Therefore, the maturation status of DCs, as the predominant APCs, after anticancer therapy or after co-incubation with in vitro-treated dying cancer cells is an attractive marker of stimulation of an immune response, specifically relying on effector $\mathrm{CD} 4^{+} / \mathrm{CD} 8^{+} \mathrm{T}$ cells (characterized by increased $\mathrm{T}$ cell proliferation/infiltration and secretion of IFN $\gamma$ ) (48).

Interestingly, cancer cells treated with most anticancer therapies either induce full DC maturation (a very small fraction of therapies) or do not stimulate the DCs at all (i.e., immature or tolerogenic DC formation, induced by a large fraction of therapies). There are however, a limited number of therapies that can also induce the formation of semi-mature DCs. In the next section, the formation of fully mature and semi-mature DCs will be discussed within the context of anticancer therapies.

\section{FULLY MATURE DCs}

Only few therapies have been reported to have the capability to induce cancer cell death that stimulates complete DC maturation. By complete maturation of DCs we understand induction of both, phenotypic markers and production of immune-stimulating cytokines. Instead, to the best of our knowledge, in most in vitro studies, the analysis of cytokine expression profile is either incomplete, or the most important cytokines, e.g., IL-12p70, IL-10, are not included. Only such fully mature DCs are able to stimulate $\mathrm{T}$ cells, hereby increasing their proliferation and secretion of IFN $\gamma$, which are often considered to be surrogate indicators of a productive immune stimulation. Thereby, in the absence of information on the full pattern of cytokines released by DCs', an increase in $\mathrm{T}$ cell stimulation can be considered a strong indicator of a full maturation state of the aforementioned DCs. Moreover, full maturation of DCs can be assumed with high probability if 
anticancer immunity in syngenic mice vaccination models (e.g., B16 cells in C57Bl/6 mice, MCA205 cells in C57Bl/6 mice, CT26 cells in $\mathrm{BALB} / \mathrm{c}$ mice, $67 \mathrm{NR}$ cells in $\mathrm{BALB} / \mathrm{c}$ mice) is achieved when dying cancer cells, following chemotherapy in vitro, are administered (either in a prophylactic or curative set-up). An anticancer treatment that can induce productive maturation of dying cancer cell-loaded DCs, at least in vitro, is Hyp-PDT (37, 49-51). Already for some time it is known that Hyp-PDT-treated cancer cells induce both phenotypic and functional maturation of DCs $(37,50)$ and that in mice vaccination experiments, the dying cancer cells stimulate anticancer immunity preventing growth of transplantable tumors (37). Recently this data was re-confirmed and extended further (50). DCs interacting with Hyp-PDT-treated cancer cells exhibit a fully mature immunogenic phenotype functionally characterized by significant secretion of immunostimulatory factors like IL-1 $\beta$, IL- 6 , nitric oxide, and the absence of the immunosuppressive cytokine, IL-10 (50). Moreover, Hyp-PDTtreated cancer cells elicit secretion of IL-12p70 by loaded DCs (Dudek et al., unpublished data).

Other treatments for which the detailed immune-effects have been described include UVB irradiation, cyclophosphamide, and $\gamma$-irradiation. There is evidence that UVB-induced dying cancer cells are phagocytosed by DCs, leading to an increase in IL-12 production (52). Furthermore, DCs pulsed with UVB-treated B16F10 cells, induce anti-tumor immunity in mice and prevent growth of transplantable tumors (52). As cyclophosphamide requires hepatic activation, for in vitro investigations its analog, MAFO, is used. Exposure of DCs to mafosfamide (MAFO)-treated cancer cells causes phenotypic maturation of DCs and their functional stimulation, characterized by the release of various cytokines (IL-1 $\beta$, IL6 , IL-12) $(53,54)$. Moreover, the treatment with cyclophosphamide of tumor-bearing mice results in increased tumor bed infiltration by phenotypically mature DCs $(53,55-57)$, as well as increased trafficking of DCs from the tumor bed to the draining lymph nodes (53). Furthermore, cyclophosphamide, when given to patients at metronomic doses, combines direct effects on immune cells, like: limitation of $\mathrm{T}_{\text {reg }}$ cells population and expansion of DCs in peripheral blood $(56,57)$ with potent stimulation of a DC response. Also $\gamma$-irradiated murine melanoma cells are efficiently phagocytosed by DCs, resulting in their phenotypic maturation $(58,59)$. Despite the fact that neither IL-12p70 nor TNF are secreted by loaded DCs, these cells release another pro-inflammatory cytokine, IL6 (59). These observations prove the triggering of a functional, however not optimal (lack of IL-12p70), maturation of loaded DCs. The positive immunostimulatory effects of $\gamma$-irradiation were shown by increased tumor-infiltrating active DCs following local high-dose radiotherapy $(60,61)$. Furthermore, when human monocyte-derived DCs and irradiated melanoma cells were coincubated with $\mathrm{T}$ cells, $\mathrm{T}$ cell-derived IFN $\gamma$ secretion increased (62), an observation that was also substantiated in vivo when irradiation of established B16F10 tumors resulted in an increase of IFN $\gamma$-producing spleen cells (63).

However, as mentioned, complete analysis of the effects of drug-treated cancer cells on DC maturation is limited to only few therapies. Other treatments are simply hypothesized or speculated to induce fully mature DC phenotype, but these are claims supported by only indirect data. Table $\mathbf{1}$, recapitulates the available information about DCs-stimulating capacities of anticancer treatments.

Besides these conventional/experimental anticancer treatments, it is also emerging that targeted therapies can induce cancer cell death, capable of affecting DC maturation status. One such therapy is Vemurafenib (PLX4032), the inhibitor of mutated $\mathrm{BRAF}^{\mathrm{V} 600 \mathrm{E}}$ kinase, which is predominantly used in patients with melanoma. Incubation of cancer cells (that harbor $\mathrm{BRAF}^{\mathrm{V} 600 \mathrm{E}}$ mutation) with iDCs followed by poly(I:C) stimulation of the latter, down-regulated the release of TNF and IL-12 (IL-12 being crucial for effective functional maturation of DCs) (64). However, when cancer cells were pre-treated with Vemurafenib, the release of TNF and IL-12 from poly(I:C) matured DCs was re-established to a level obtained in the control (matured DCs without cancer cells) (64). Moreover Vemurafenib is known to increase TAA levels, such as MART1 and gp100 (65).

In conclusion, in future it is necessary to find and test more ICD inducers in order to better understand the diversity that fully mature DCs may exhibit in terms of activation characteristics. Also, it would be necessary to (re-)analyze certain existing therapies for their potential to cause DC maturation irrespective of whether they induced ICD.

\section{SEMI-MATURE DCs}

In the literature, evidence indicates that some anticancer treatments may cause "moderate" stimulation of an immune response. Under such circumstances the immune system activating signals are not strong enough or not persistent enough to establish a stable anticancer immunity. For DCs, this means that these APCs lack either the required phenotypic maturation markers and thereby are not capable to efficiently interact with $\mathrm{T}$ cells, or the required signature cytokine pattern released from loaded DCs and ultimately resulting in "immunocompromising" actions. Tolerogenicity induced by semi-mature DCs is connected with release of immunosuppressive cytokines like IL-10, TGF- $\beta$ (66), plasma membrane expression of programed cell death ligands, like PD-L1 or PD-L2 (67), and with stimulation of $\mathrm{T}_{\text {regs }}$ expansion (67).

\section{Phenotypically mature DCs}

A good example of a treatment that induces phenotypic maturation of DCs, independent of the immunostimulating profile of cytokines is bevacizumab. This epidermal growth factor receptor (EGFR)-blocking antibody, which blocks angiogenesis, only induced phenotypic maturation of DCs upon their co-incubation with treated cancer cells (68). Nevertheless it should be highlighted that, on the one hand, addition of bevacizumab to co-cultures resulted in increased IL-6, but decreased IL-12 release (68). Moreover, it was shown that bevacizumab-treatment of patients with metastatic colorectal cancer increased total lymphocyte number (69) and had the potential to increase extravasation of T cells into the tumor bed, previously observed for the therapeutic paradigm of anti-EGFR antibody combined with adoptively transferred $\mathrm{T}$ cells in mice models (70).

Furthermore, cetuxinib, another EGFR-blocking antibody that prevents signaling from growth factors, shows similar results. Despite the fact that colon cancer cells treated in vitro with cetuxinib were phagocytosed by iDC (71) and induced the up-regulation 
of maturation markers (72), there is no investigation, till now, of the cytokines required for characterization of maturation status of these DCs. Thus this treatment should not be incorporated into the group of therapies that induce "full mature DCs" - as of now. Nevertheless, cetuxinib treatment has other features that demonstrate its positive effect on the immune system: its capacity to stimulate NK cell mediated antibody-dependent cellular cytotoxicity and complement-dependent cytotoxicity, are well documented (72).

Finally sunitinib (an inhibitor of receptor tyrosine kinase)treated melanoma cells enhanced the maturation status of DCs (measured by the percentage of $\mathrm{CD}^{+} 6^{+}$cells). However no investigation of DC-secreted cytokines has been performed. In spite of this, one can be relatively positive about its immunoinhibitory effects, as cytotoxic T lymphocytes (CTLs) incubated with these loaded DCs did not increase their secretion of IL-6 (73).

Thus, while in some cases, certain therapeutic treated cancer cells induce formation of semi-mature DCs, yet for others the indications in this direction are either mixed or poorly studied. More analysis is required on the cytokine levels to ascertain whether such therapeutics are able to cause formation of semi-mature DCs or not. Last but not least, it is also necessary to analyze further the direct effects of anticancer treatments on DCs maturation (in set-ups where these therapies are not intended to directly affect the DCs) - an aspect that has received the least attention in studies addressing DC-based immunity.

\section{DC-BASED CANCER IMMUNOTHERAPY}

Most of the clinically used anticancer therapies if systemically administered strongly affect not only cancer cells but as well the cells from tumor microenvironment, systemic hematopoietic cells, and rapidly dividing bone marrow cells. Despite the fact that recently platinum-based drugs, at clinically applicable concentrations, have been shown to enhance cytokine-induced DC maturation in vitro (74), vast majority of the effects on the non-cancer cells are of negative nature (i.e., prevention of differentiation of new immune cells from progenitor bone marrow cells and lymphopenia or leukopenia). These actions reduce the number of immune cells capable of sensing the danger and immune-stimulating signals released by dying cancer cells thereby compromising anticancer immunity. To evade this effect, a DCbased immunotherapy approach can be employed in a couple of ways: (1) by directly targeting/stimulating the DCs in vivo so as to accentuate their anticancer phenotype or (2) by stimulating the DCs ex vivo and infusing them back into the host for carrying out anticancer effector function.

Starting from 1998 there were few trials testing the in vivo DCs' stimulation with synthetic peptides (75-77). Most of them however failed as they were unable to effectively stimulate $\mathrm{CD} 4^{+}$cellular responses $(75,78,79)$ and stimulation of Th2 type cytokines $(80,81)$. Learning from the abovementioned studies, Walter et al. showed that patients pre-treated with single-dose cyclophosphamide as well as vaccinated with TAAs peptides and granulocyte macrophage colony stimulating factor (GM-CSF), showed clinical responses in Phase I and II trials (82). To further improve the peptide/protein anticancer vaccines the idea of combining TLR agonist administration with the vaccines emerged. The idea was taken up by GlaxoSmithKline that invented AS15 adjuvant that combines TLR4 and TLR9 agonists (83). Patients with MAGE-A3 ${ }^{+}$ melanoma administered with MAGE-A3 peptide in combination with AS15 in Phase II trial (NCT00086866 and NCT00290355) showed clinical activity (84). The study is being followed up by a Phase III trial.

An alternative, to direct in vivo DCs' stimulation is, isolation of DCs' precursors from the patient (through leukapheresis) and maturation/stimulation of these precursors ex vivo followed by allogeneic injection of these fully mature DCs back into the patient. Nowadays there are various ways applied to generate cancer cellsspecific DCs: the stimulation can be done with specific TAAs (full length or short peptides), tumor lysates (freeze-thawed or acid eluted), electroporation/transfection of DCs with total cancer cell-mRNA, creating DC-cancer cell fusions, or with tumor derived exosomes (TDEs) (as discussed below). Alternatively DCs can also be genetically manipulated to express specific TAAs. Moreover as the stimulation is performed ex vivo there is a possibility to additionally co-stimulate with cytokine "cocktails" to assure their strong maturation. For example in 2010 a Provenge treatment strategy on similar lines got approved by FDA for therapy of patients with castration-resistant prostate cancer (85). The treatment consists of ex vivo stimulation of DCs with PA2024 that is a fusion protein of prostatic acid phosphatizes (TAA present in $95 \%$ of this type of tumor) and GM-CSF. The Phase III clinical trial revealed increased overall survival of patients treated with Provenge in comparison to placebo $(86,87)$.

Currently, there are many Phase I, II, and III clinical trials that test the effect of different anticancer DC vaccination strategies on various cancer types. The running/finalized clinical trials were recently thoroughly summarized by Galluzzi et al. thus we refer readers interested in this topic to "Trial Watch" publication (88).

\section{EXOSOMES; AS LONG DISTANCE MESSENGERS, MODULATORS, OR SUPPRESSORS OF DC-ASSOCIATED ANTICANCER IMMUNITY?}

Phenotypic maturation and functional stimulation are wellestablished markers of DC maturation as well as the ability of DCs to "prime" anticancer immune responses (9). Modulation of these two relevant DC-associated biological parameters by cancer cells (on the levels of TAAs, DAMPs, or danger signals and cytokines/chemokines) is considered to make the difference between immature, semi-mature, and mature DCs (2, 7, $35,40)$, as discussed above. However, depending on the anticancer therapy under consideration, DC markers and cancer cellbased modulators sometime fail to completely account for the observed failure of or reduction in anticancer immunity (89). Thereby these may point toward other DC or cancer cell-based autocrine or paracrine modulators of immunity which are capable of transmitting signals (21).

One vehicle type capable of long distant transport of cellular material are the endosome-derived nano-vesicles, known as exosomes (90). These vesicles are derived by inward budding of the multi-vesicular body membrane and have been implicated in cell-cell communication (91). Historically, exosomes were classified as a simple mechanism for the removal of unwanted cellular material $(92,93)$, yet more recently they have been implicated in the transmission of signals between cells, both locally and over 
long distances, effecting cells of different lineages, demonstrating the capacity to influence cellular signaling, and outcomes of stress responses (94-96). Where the physiological outcome depends on both the type of cell the exosome originates from and the type of stress the cell is exposed to, known to alter protein and lipid signatures in a context-dependent manner.

Certain cancer cells are known to exaggerate their generation of exosomes, demonstrating constitutive release, delivering tumor derived signals throughout the local tumor microenvironment and beyond within various body fluids $(97,98)$. These signals have been implicated in the transmission of pro-tumorigenic, angiogenic, and metastatic signals, as well as factors capable of stimulating/inhibiting immune responses $(97,99,100)$. Here we will focus on the dynamic relationships that exist between the signals released or received between cancer cells and DCs and highlight key components that may sway the outcome in the context on anticancer immunity.

\section{THE EFFECT OF CANCER-DERIVED EXOSOMES ON DENDRITIC CELLS}

Antigen acquisition by DCs is an essential step in the induction of antigen-mediated immune responses. These antigens can be sequestered by DCs in the form of infectious agents, dying infected cells or in the case of tumors, by the engulfment of dying cells or exosomes that are secreted by living/stressed or dying cells. As the protein signature of an exosome is dependent on the cell of origin as well as their viability, TDEs are abundant in TAAs (Her2/Neu, MART1, TRP1/2, gp100) (101), antigen-presenting molecules (MHC class I, heat-shock proteins) (102), as well as varying tetraspanins (such as CD81) (103-105). These privileged carriers of antigens and immunostimulatory molecules exposed on exosomes have been shown to activate DCs (101). Research identified that exosomes could induce phenotypic and functional maturation of DCs, demonstrating enhanced cell surface expression of MHC-II, CD80, CD86, and CD40 as well as increased IL12 p70 production (106). For example, melanoma exosomes were shown to deliver MART1 tumor antigens to monocyte-derived DCs, allowing for successful cross-presentation (101). Moreover, in vivo assessment of TDEs capacity for immunomodulation demonstrated their potential to prevent autologous tumor development, in a CD4/CD8-dependent manner (107). TDE mediated DC maturation and antigen presentation (MHC-II and ICAM) propagates $\mathrm{T}$ cell stimulation, demonstrated by increased $\mathrm{CD} 4^{+}$ and $\mathrm{CD}^{+}$T-cell proliferation, the induction of enhanced CTL based tumor cell lysis $(108,109)$ and the generation of Th1type memory (110). Moreover, exosomes derived from DC cells exposed to TAAs demonstrate 50-fold higher efficiency and 3fold higher $\mathrm{T}$ cell activation potential than non-TAA exposed controls (109).

Conversely, other studies have demonstrated the immunosuppressive nature of TDEs. Work into the role of TDEs highlighted their tumor suppressor potential (111), however the majority of data, till now, indicates a more potent immunosuppressive nature. For example, TDEs can prevent DC differentiation in vitro, in such a manner that a pool of CD14 ${ }^{+} \mathrm{HLA}-\mathrm{DR}{ }^{\text {neg/low }}$ cells was generated, culminating in the marked reduction of autologous $\mathrm{T}$ cell stimulation (112). Also, in vivo experiments demonstrated an accumulation of undifferentiated myeloid cells in the spleen of mice after
TDEs administration, consequently resulting in the formation of a DC population that was incapable of maturation (99). Furthermore, this inhibition of DC maturation/differentiation was also observed in human monocytes, following exposure to TDEs (99). Moreover, TDEs have the potential to activate myeloid derived suppressor cells (MDSCs), hampering immune responses, in this case via $\mathrm{T}_{\text {regs }}(113)$.

The potential for TDE to influence an immune response has generated contrasting bodies of research. However these observations may both be true and simply a consequence of experimental design. For instance, time is an important issue for response outcome when the TDE interact with immune cells. Yu et al. investigating the effect of TDE on bone marrow derived myeloid precursors, described a significant reduction in DC differentiation, induced by treatment with GM-CSF, when the exposure occurred within 3 days (99). In contrast, Andre et al. showed that pulsing iDCs with TDE, after 5 days of GM-CSF treatment, resulted in an observed DC-mediated T cell response (101). Moreover, research into the effect of TDE, on induction of cytokine release from monocytes, demonstrated that a cacophony of pro-inflammatory cytokines (such as TNF, IL-6), as well as immunosuppressive factors (such as IL-8, IL-10, TGF- $\beta$ ) (114) were released. Importantly immunosuppression was predominantly mediated via TGF- $\beta$. The ability of TDE to induce IL- 6 expression and/or release has been implicated in their inhibition of myeloid precursor differentiation, as well as accentuating the immunosuppressive capacity of MDSC, which were themselves activated by TDEs (99). Furthermore, research demonstrated enhanced exosomal HSP72, induced by IFN $\gamma$ stimulation of tumor cells, resulted in the upregulation of CD83 and potentiation of IL-12 production in DCs (115).

Alterations in cancer dendritic cell-derived exosome (DEX) expression of key immune-modulators have been shown to be evoked by both tumor microenvironmental stress as well as cellular stress induced by anticancer therapies, both traditional and targeted approaches (101-105). However, due to the vast number of cell types that excrete exosomes, little is known about the effect of therapy specifically on exosome-based host immune activation in clinical settings. However, research in vitro has demonstrated significant enrichment of TAAs as a consequence of therapy. Moreover, combination therapy with exosomes and DNA alkylating agents (such as cyclophosphamide) significantly potentiated cancer killing compared to single agent $(117,118)$. Fortunately, due to the biomarker potential of exosomes, progress into exosomal population isolation is allowing further investigations of the immunomodulatory and overall clinical potential of TDEs (116).

Importantly, the mode of antigen secretion can also alter the immunogenicity toward TAAs (119). Antigens loaded into nanovesicles were shown to incite a significantly stronger immune response, than when the same antigens were secreted freely. Therefore the manipulation of how antigens are presented to immune cells may be used to enhance the success of anti-tumor vaccinations (107). So, due to the contradictory effects of TDE on DC-induced immune responses, the concept of TDE as a targetedcancer therapy was quickly surpassed by the use of safer and more focused DC-DEXs, loaded with TAAs $(120,121)$. 


\section{THE EFFECT OF DENDRITIC CELL-DERIVED EXOSOMES ON CANCER CELLS}

The potential for endogenous DEXs to induce anticancer responses remains unclear. However, existing research has identified that DEXs express, on their surface, multiple TNF superfamily ligands (122). Through these ligands they can incite anticancer immunity directly via the induction of cancer cell apoptosis, as well as indirectly through the activation of NK cells $(122,123)$. Recent work shows that similar to DCs, DEXs contain TNF, FasL, and TRAIL. These ligands have the potential to trigger caspase activation and apoptosis in a tumor cell models (122). Moreover, DEXs can also activate NK cells and stimulate their IFN $\gamma$ secretion, inciting immune responses $(122,123)$.

However, research over the past decade has highlighted more the use of engineered DEX as a feasible and successful route to activate anti-tumor modalities in vivo $(123,124)$, that has gone on to demonstrate success clinically (120). Interestingly, treatment with engineered DEXs has shown a stronger anticancer effect than the use of the DCs they are derived from to re-activate downstream immune responses. These observations may in part be explained by the immunosuppressive effect of the tumor microenvironment on DC phenotypic functionality (125). Zitvogel and colleagues demonstrated a perturbation in growth of mastocytoma and spontaneous mammary carcinoma tumors by day 10 , following inoculation with DEXs, derived from bone marrow DC that were pulsed with acid eluted tumor antigens (107). Furthermore, by day $60 \sim 50 \%$ of mice treated with DEXs were diagnosed tumor free (107). Interestingly, when re-challenged, the mice demonstrated tumor rejection unless inoculated with a differing cancer type, implying long-lasting anti-tumor immunity stimulated by DEXs (107). Furthermore, Taieb et al. investigating the combination of DEXs with cyclophosphamide showed that DEXs were capable of boosting the immune response toward immunogenic cancers, showing synergistic tumoricidial potency toward pre-established tumors (118).

Elegant research into the potential of DEXs as anticancer modulators demonstrated that DEXs harvested from bone marrow derived DCs that had been stimulated by LPS treatment mature dendritic cells derived exosomes (mDEXs), compared to untreated immature dendritic cells derived exosomes (imDEXs), were significantly enriched in molecules (such as ICAM-1) capable of mediating $\mathrm{T}$ cell priming, enhanced $\mathrm{T}$ cell proliferation and the stimulation of naïve $\mathrm{T}$ cells to differentiate and produce cytokines (108). The research of Naslund and colleagues showed that DEX treatment induced $\mathrm{T}$ cell responses, yet in a B cell-dependent manner (126). This suggests that immunization with DEXs carrying only peptides for $\mathrm{T}$ cells would induce a sub-optimal response (126). Furthermore, protein-loaded rather than peptide-loaded DEXs showed greater $\mathrm{T}$ cell responses in vivo and a superior antitumor capacity (126). Interestingly, the induced $\mathrm{T}$ cell response requires the presence of $B$ cells and mice deficient in complement activation and antigen shuttling by B cells had reduced DEXsinduced responses (126). Solidifying the dynamics of exosomal signaling in immune cell activation and anti-tumor immunity, DEXs secreted into the extracellular milieu during cognate $\mathrm{T}$ cell-DC interactions, are targeted and engulfed specifically by
T cells, via the leukocyte function-associated antigen-1 (LFA-1) receptor (127).

Moreover, findings from preliminary Phase I clinical trials for the use of DEXs as a treatment for stage IV melanoma and nonsmall cell lung cancer, demonstrated a restoration of NK cell activity in over $50 \%$ of patients $(107,120)$. This increase in NK cell activity was shown to stimulate their cell killing capacity in vitro (120). Therefore, their lipid composition, that itself possesses adjuvant qualities and exosome stability within the circulation (128-130), coupled with simultaneous expression of MHC class I and II molecules, as well as a plethora of co-stimulatory molecules $(102,131)$, may indicate the cocktail of requirements that deem DEXs capable to incite anti-tumor or pro-immunogenic effects. Furthermore, the reported lack of toxicity highlights DEX-based therapies as an interesting modality for cancer therapy $(107,120)$. Further to this, investigation on combination of DEX-targeted therapies with traditional therapeutics or other modern targeted approaches should be done to explore their potential to restore immune activity in the fight against cancer.

\section{CONCLUDING REMARKS}

The induction of an efficient anticancer immune response is thought to contribute to the success of anticancer treatments, by the establishment of a robust $\mathrm{T}$ cell mediated response capable of sustaining long-term control of cancer. Upon activation, DCs are crucial inducers of $\mathrm{T}$ cell immunity and are therefore at the frontline of immune-regulated responses. Hence, triggering proper maturation of DCs is an outstanding therapeutic objective as it may boost anti-tumor immunity and thwart cancer-induced immunosuppression. The discovery of different DCs sub-populations that exhibit wide functional plasticity has made the initial dichotomy between immature/tolerogenic and mature/immunogenic DCs, obsolete. However, in spite of a functional definition of these DCs phenotypes, which ranges from tolerogenic, partial/semi-mature to fully mature DCs, it still remains challenging to understand how, when, and to what extent this dynamic spectrum of DC activation drives tumorspecific tolerance or anti-tumor immunity, also in the context of anticancer therapy. In this respect, the existing (mostly immunosuppressive) or therapy-generated tumor microenvironments and the cross-talk between (dying) cancer cells and DCs, established through soluble (cytokines/chemokines) and vesicular (exosomes) mediators, are emerging as crucial determinants of DC maturation status and anticancer immune responses. Future preclinical research combined with clinical investigations, will disclose whether therapeutics inducing immunogenic cancer cell death, will meet the therapeutic objective of re-establishing the proper interface between dying cancer cells and DCs, promoting their fully mature/immunogenic status that is required to sustain anti-tumor immunity.

\section{REFERENCES}

1. Janeway CA Jr, Medzhitov R. Innate immune recognition. Annu Rev Immunol (2002) 20:197-216. doi:10.1146/annurev.immunol.20.083001.084359

2. Steinman RM, Idoyaga J. Features of the dendritic cell lineage. Immunol Rev (2010) 234:5-17. doi:10.1111/j.0105-2896.2009.00888.x 
3. Vesely MD, Kershaw MH, Schreiber RD, Smyth MJ. Natural innate and adaptive immunity to cancer. Annu Rev Immunol (2011) 29:235-71. doi:10.1146/ annurev-immunol-031210-101324

4. Matzinger P. The danger model: a renewed sense of self. Science (2002) 296:301-5. doi:10.1126/science.1071059

5. Martin SJ, Henry CM, Cullen SP. A perspective on mammalian caspases as positive and negative regulators of inflammation. Mol Cell (2012) 46:387-97. doi:10.1016/j.molcel.2012.04.026

6. Green DR, Ferguson T, Zitvogel L, Kroemer G. Immunogenic and tolerogenic cell death. Nat Rev Immunol (2009) 9:353-63. doi:10.1038/nri2545

7. Garg AD, Dudek AM, Agostinis P. Cancer immunogenicity, danger signals, and DAMPs: what, when, and how? Biofactors (2013) 39:355-67. doi:10.1002/biof. 1125

8. Garg AD, Nowis D, Golab J, Vandenabeele P, Krysko DV, Agostinis P. Immunogenic cell death, DAMPs and anticancer therapeutics: an emerging amalgamation. Biochim Biophys Acta (2010) 1805:53-71. doi:10.1016/j.bbcan.2009.08. 003

9. Reis e Sousa C. Dendritic cells in a mature age. Nat Rev Immunol (2006) 6:476-83. doi:10.1038/nri1845

10. Lutz MB, Schuler G. Immature, semi-mature and fully mature dendritic cells: which signals induce tolerance or immunity? Trends Immunol (2002) 23:445-9. doi:10.1016/S1471-4906(02)02281-0

11. Garg AD, Martin S, Golab J, Agostinis P. Danger signalling during cancer cell death: origins, plasticity and regulation. Cell Death Differ (2013). doi:10.1038/cdd. 2013.48

12. Mellman I. Dendritic cells: master regulators of the immune response. Cancer Immunol Res (2013) 1:145. doi:10.1158/2326-6066.CIR-13-0102

13. Simmons DP, Wearsch PA, Canaday DH, Meyerson HJ, Liu YC, Wang Y, et al. Type I IFN drives a distinctive dendritic cell maturation phenotype that allows continued class II MHC synthesis and antigen processing. J Immunol (2012) 188:3116-26. doi:10.4049/jimmunol.1101313

14. Reis e Sousa C. Toll-like receptors and dendritic cells: for whom the bug tolls. Semin Immunol (2004) 16:27-34. doi:10.1016/j.smim.2003.10.004

15. Romao S, Gannage M, Munz C. Checking the garbage bin for problems in the house, or how autophagy assists in antigen presentation to the immune system. Semin Cancer Biol (2013) 23:391-6. doi:10.1016/j.semcancer.2013.03.001

16. Garg AD, Dudek AM, Agostinis P. Autophagy-dependent suppression of cancer immunogenicity and effector mechanisms of innate and adaptive immunity. Oncoimmunology (2013) 2:e26260. doi:10.4161/onci.26260

17. Garg AD, Kaczmarek A, Krysko O, Vandenabeele P, Krysko DV, Agostinis P. ER stress-induced inflammation: does it aid or impede disease progression? Trends Mol Med (2012) 18:589-98. doi:10.1016/j.molmed.2012.06.010

18. Henrickson SE, Perro M, Loughhead SM, Senman B, Stutte S, Quigley $\mathrm{M}$, et al. Antigen availability determines CD8(+) T cell-dendritic cell interaction kinetics and memory fate decisions. Immunity (2013) 39:496-507. doi:10.1016/j.immuni.2013.08.034

19. Miller MJ, Hejazi AS, Wei SH, Cahalan MD, Parker I. T cell repertoire scanning is promoted by dynamic dendritic cell behavior and random $\mathrm{T}$ cell motility in the lymph node. Proc Natl Acad Sci U S A (2004) 101:998-1003. doi:10.1073/pnas.0306407101

20. Sallusto F, Cella M, Danieli C, Lanzavecchia A. Dendritic cells use macropinocytosis and the mannose receptor to concentrate macromolecules in the major histocompatibility complex class II compartment: downregulation by cytokines and bacterial products. J Exp Med (1995) 182:389-400. doi:10.1084/ jem.182.2.389

21. Maes H, Rubio N, Garg AD, Agostinis P. Autophagy: shaping the tumor microenvironment and therapeutic response. Trends Mol Med (2013) 19:428-46. doi:10.1016/j.molmed.2013.04.005

22. Pardoll DM. The blockade of immune checkpoints in cancer immunotherapy. Nat Rev Cancer (2012) 12:252-64. doi:10.1038/nrc3239

23. Engelhardt JJ, Boldajipour B, Beemiller P, Pandurangi P, Sorensen C, Werb Z, et al. Marginating dendritic cells of the tumor microenvironment cross-present tumor antigens and stably engage tumor-specific T cells. Cancer Cell (2012) 21:402-17. doi:10.1016/j.ccr.2012.01.008

24. Chiba S, Baghdadi M, Akiba H, Yoshiyama H, Kinoshita I, Dosaka-Akita H, et al. Tumor-infiltrating DCs suppress nucleic acid-mediated innate immune responses through interactions between the receptor TIM-3 and the alarmin HMGB1. Nat Immunol (2012) 13:832-42. doi:10.1038/ni.2376
25. Vicari AP, Caux C, Trinchieri G. Tumour escape from immune surveillance through dendritic cell inactivation. Semin Cancer Biol (2002) 12:33-42. doi:10.1006/scbi.2001.0400

26. Ma Y, Shurin GV, Peiyuan Z, Shurin MR. Dendritic cells in the cancer microenvironment. J Cancer (2013) 4:36-44. doi:10.7150/jca.5046

27. Krysko DV, Garg AD, Kaczmarek A, Krysko O, Agostinis P, Vandenabeele P. Immunogenic cell death and DAMPs in cancer therapy. Nat Rev Cancer (2012) 12:860-75. doi:10.1038/nrc3380

28. Casares N, Pequignot MO, Tesniere A, Ghiringhelli F, Roux S, Chaput N, et al. Caspase-dependent immunogenicity of doxorubicin-induced tumor cell death. J Exp Med (2005) 202:1691-701. doi:10.1084/jem.20050915

29. Mempel TR, Henrickson SE, Von Andrian UH. T-cell priming by dendritic cells in lymph nodes occurs in three distinct phases. Nature (2004) 427:154-9. doi: $10.1038 /$ nature 02238

30. Henrickson SE, Mempel TR, Mazo IB, Liu B, Artyomov MN, Zheng H, et al. $\mathrm{T}$ cell sensing of antigen dose governs interactive behavior with dendritic cells and sets a threshold for T cell activation. Nat Immunol (2008) 9:282-91. doi:10.1038/ni1559

31. Bonmort M, Dalod M, Mignot G, Ullrich E, Chaput N, Zitvogel L. Killer dendritic cells: IKDC and the others. Curr Opin Immunol (2008) 20:558-65. doi:10.1016/j.coi.2008.04.006

32. Lu G, Janjic BM, Janjic J, Whiteside TL, Storkus WJ, Vujanovic NL. Innate direct anticancer effector function of human immature dendritic cells. II. Role of TNF, lymphotoxin-alpha(1)beta(2), Fas ligand, and TNF-related apoptosisinducing ligand. J Immunol (2002) 168:1831-9.

33. Janjic BM, Lu G, Pimenov A, Whiteside TL, Storkus WJ, Vujanovic NL. Innate direct anticancer effector function of human immature dendritic cells. I. Involvement of an apoptosis-inducing pathway. J Immunol (2002) 168:1823-30.

34. Kim R, Emi M, Tanabe K. Cancer immunoediting from immune surveillance to immune escape. Immunology (2007) 121:1-14. doi:10.1111/j.1365-2567.2007. 02587.x

35. Kroemer G, Galluzzi L, Kepp O, Zitvogel L. Immunogenic cell death in cancer therapy. Annu Rev Immunol (2013) 31:51-72. doi:10.1146/annurev-immunol032712- 100008

36. Martins I, Kepp O, Schlemmer F, Adjemian S, Tailler M, Shen S, et al. Restoration of the immunogenicity of cisplatin-induced cancer cell death by endoplasmic reticulum stress. Oncogene (2011) 30:1147-58. doi:10.1038/onc. 2010.500

37. Garg AD, Krysko DV, Verfaillie T, Kaczmarek A, Ferreira GB, Marysael T, et al. A novel pathway combining calreticulin exposure and ATP secretion in immunogenic cancer cell death. EMBO J (2012) 31:1062-79. doi:10.1038/emboj.2011. 497

38. Barratt-Boyes SM, Zimmer MI, Harshyne LA, Meyer EM, Watkins SC, Capuano S III, et al. Maturation and trafficking of monocyte-derived dendritic cells in monkeys: implications for dendritic cell-based vaccines. J Immunol (2000) 164:2487-95.

39. Sapoznik S, Hammer O, Ortenberg R, Besser MJ, Ben-Moshe T, Schachter J, et al. Novel anti-melanoma immunotherapies: disarming tumor escape mechanisms. Clin Dev Immunol (2012) 2012:818214. doi:10.1155/2012/818214

40. Dudek AM, Garg AD, Krysko DV, De Ruysscher D, Agostinis P. Inducers of immunogenic cancer cell death. Cytokine Growth Factor Rev (2013) 24:319-33. doi:10.1016/j.cytogfr.2013.01.005

41. Grivennikov SI, Greten FR, Karin M. Immunity, inflammation, and cancer. Cell (2010) 140:883-99. doi:10.1016/j.cell.2010.01.025

42. Garg AD, Krysko DV, Vandenabeele P, Agostinis P. The emergence of phoxER stress induced immunogenic apoptosis. Oncoimmunology (2012) 1:786-8. doi:10.4161/onci.19750

43. Hodge JW, Garnett CT, Farsaci B, Palena C, Tsang KY, Ferrone S, et al. Chemotherapy-induced immunogenic modulation of tumor cells enhances killing by cytotoxic T lymphocytes and is distinct from immunogenic cell death. Int J Cancer (2013) 133:624-36. doi:10.1002/ijc.28070

44. Segura E, Touzot M, Bohineust A, Cappuccio A, Chiocchia G, Hosmalin A, et al. Human inflammatory dendritic cells induce Th17 cell differentiation. Immunity (2013) 38:336-48. doi:10.1016/j.immuni.2012.10.018

45. Ma Y, Aymeric L, Locher C, Mattarollo SR, Delahaye NF, Pereira P, et al. Contribution of IL-17-producing gamma delta T cells to the efficacy of anticancer chemotherapy. J Exp Med (2011) 208:491-503. doi:10.1084/jem.20100269 
46. Martin F, Apetoh L, Ghiringhelli F. Controversies on the role of Th17 in cancer: a TGF-beta-dependent immunosuppressive activity? Trends Mol Med (2012) 18:742-9. doi:10.1016/j.molmed.2012.09.007

47. Zou W, Restifo NP. T(H) 17 cells in tumour immunity and immunotherapy. Nat Rev Immunol (2010) 10:248-56. doi:10.1038/nri2742

48. Steinman RM, Mellman I. Immunotherapy: bewitched, bothered, and bewildered no more. Science (2004) 305:197-200. doi:10.1126/science.1099688

49. Garg AD, Dudek AM, Agostinis P. Calreticulin surface exposure is abrogated in cells lacking, chaperone-mediated autophagy-essential gene, LAMP2A. Cell Death Dis (2013) 4:e826. doi:10.1038/cddis.2013.372

50. Garg AD, Dudek AM, Ferreira GB, Verfaillie T, Vandenabeele P, Krysko DV, et al. ROS-induced autophagy in cancer cells assists in evasion from determinants of immunogenic cell death. Autophagy (2013) 9:1292-307. doi:10.4161/auto. 25399

51. Garg AD, Krysko DV, Vandenabeele P, Agostinis P. Hypericin-based photodynamic therapy induces surface exposure of damage-associated molecular patterns like HSP70 and calreticulin. Cancer Immunol Immunother (2012) 61:215-21. doi:10.1007/s00262-011-1184-2

52. Kotera Y, Shimizu K, Mule JJ. Comparative analysis of necrotic and apoptotic tumor cells as a source of antigen(s) in dendritic cell-based immunization. Cancer Res (2001) 61:8105-9.

53. Schiavoni G, Sistigu A, Valentini M, Mattei F, Sestili P, Spadaro F, et al. Cyclophosphamide synergizes with type I interferons through systemic dendritic cell reactivation and induction of immunogenic tumor apoptosis. Cancer Res (2011) 71:768-78. doi:10.1158/0008-5472.CAN-10-2788

54. Nakahara T, Uchi H, Lesokhin AM, Avogadri F, Rizzuto GA, HirschhornCymerman D, et al. Cyclophosphamide enhances immunity by modulating the balance of dendritic cell subsets in lymphoid organs. Blood (2010) 115:4384-92. doi:10.1182/blood-2009-11-251231

55. Audia S, Nicolas A, Cathelin D, Larmonier N, Ferrand C, Foucher P, et al. Increase of CD4+ CD25+ regulatory T cells in the peripheral blood of patients with metastatic carcinoma: a phase I clinical trial using cyclophosphamide and immunotherapy to eliminate CD4+ CD25+ T lymphocytes. Clin Exp Immunol (2007) 150:523-30. doi:10.1111/j.1365-2249.2007.03521.x

56. Salem ML, Diaz-Montero CM, Al-Khami AA, El-Naggar SA, Naga O, Montero AJ, et al. Recovery from cyclophosphamide-induced lymphopenia results in expansion of immature dendritic cells which can mediate enhanced primeboost vaccination antitumor responses in vivo when stimulated with the TLR3 agonist poly(I:C). J Immunol (2009) 182:2030-40. doi:10.4049/jimmunol. 0801829

57. Salem ML, Kadima AN, El-Naggar SA, Rubinstein MP, Chen Y, Gillanders WE, et al. Defining the ability of cyclophosphamide preconditioning to enhance the antigen-specific CD8+ T-cell response to peptide vaccination: creation of a beneficial host microenvironment involving type I IFNs and myeloid cells. J Immunother (2007) 30:40-53. doi:10.1097/01.cji.0000211311.28739.e3

58. Prasad SJ, Farrand KJ, Matthews SA, Chang JH, McHugh RS, Ronchese F. Dendritic cells loaded with stressed tumor cells elicit long-lasting protective tumor immunity in mice depleted of CD4+CD25+ regulatory $\mathrm{T}$ cells. J Immunol (2005) 174:90-8.

59. Kim SK, Yun CH, Han SH. Enhanced anti-cancer activity of human dendritic cells sensitized with gamma-irradiation-induced apoptotic colon cancer cells. Cancer Lett (2013) 335:278-88. doi:10.1016/j.canlet.2013.02.038

60. Huang J, Wang Y, Guo J, Lu H, Lin X, Ma L, et al. Radiation-induced apoptosis along with local and systemic cytokine elaboration is associated with DC plus radiotherapy-mediated renal cell tumor regression. Clin Immunol (2007) 123:298-310. doi:10.1016/j.clim.2007.02.005

61. Gupta A, Probst HC, Vuong V, Landshammer A, Muth S, Yagita H, et al. Radiotherapy promotes tumor-specific effector CD8+ T cells via dendritic cell activation. J Immunol (2012) 189:558-66. doi:10.4049/jimmunol.1200563

62. Strome SE, Voss S, Wilcox R, Wakefield TL, Tamada K, Flies D, et al. Strategies for antigen loading of dendritic cells to enhance the antitumor immune response. Cancer Res (2002) 62:1884-9.

63. Schaue D, Ratikan JA, Iwamoto KS, McBride WH. Maximizing tumor immunity with fractionated radiation. Int J Radiat Oncol Biol Phys (2012) 83:1306-10. doi:10.1016/j.ijrobp.2011.09.049

64. Ott PA, Henry T, Baranda SJ, Frleta D, Manches O, Bogunovic D, et al. Inhibition of both BRAF and MEK in BRAF(V600E) mutant melanoma restores compromised dendritic cell (DC) function while having differential direct effects on DC properties. Cancer Immunol Immunother (2013) 62:811-22. doi:10.1007/s00262-012-1389-z

65. Boni A, Cogdill AP, Dang P, Udayakumar D, Njauw CN, Sloss CM, et al. Selective BRAFV600E inhibition enhances T-cell recognition of melanoma without affecting lymphocyte function. Cancer Res (2010) 70:5213-9. doi:10.1158/ 0008-5472.CAN-10-0118

66. Harden JL, Egilmez NK. Indoleamine 2,3-dioxygenase and dendritic cell tolerogenicity. Immunol Invest (2012) 41:738-64. doi:10.3109/08820139.2012. 676122

67. Rutella S, Danese S, Leone G. Tolerogenic dendritic cells: cytokine modulation comes of age. Blood (2006) 108:1435-40. doi:10.1182/blood2006-03-006403

68. Yang DH, Park JS, Jin CJ, Kang HK, Nam JH, Rhee JH, et al. The dysfunction and abnormal signaling pathway of dendritic cells loaded by tumor antigen can be overcome by neutralizing VEGF in multiple myeloma. Leuk Res (2009) 33:665-70. doi:10.1016/j.leukres.2008.09.006

69. Manzoni M, Rovati B, Ronzoni M, Loupakis F, Mariucci S, Ricci V, et al. Immunological effects of bevacizumab-based treatment in metastatic colorectal cancer. Oncology (2010) 79:187-96. doi:10.1159/000320609

70. Shrimali RK, Yu Z, Theoret MR, Chinnasamy D, Restifo NP, Rosenberg SA. Antiangiogenic agents can increase lymphocyte infiltration into tumor and enhance the effectiveness of adoptive immunotherapy of cancer. Cancer Res (2010) 70:6171-80. doi:10.1158/0008-5472.CAN-10-0153

71. Correale P, Botta C, Cusi MG, Del Vecchio MT, De Santi MM, Gori Savellini $\mathrm{G}$, et al. Cetuximab \pm chemotherapy enhances dendritic cell-mediated phagocytosis of colon cancer cells and ignites a highly efficient colon cancer antigenspecific cytotoxic T-cell response in vitro. Int J Cancer (2012) 130:1577-89. doi:10.1002/ijc. 26181

72. Vanneman M, Dranoff G. Combining immunotherapy and targeted therapies in cancer treatment. Nat Rev Cancer (2012) 12:237-51. doi:10.1038/nrc3237

73. Moehler M, Sieben M, Roth S, Springsguth F, Leuchs B, Zeidler M, et al. Activation of the human immune system by chemotherapeutic or targeted agents combined with the oncolytic parvovirus H-1. BMC Cancer (2011) 11:464. doi:10.1186/1471-2407-11-464

74. Lesterhuis WJ, Punt CJ, Hato SV, Eleveld-Trancikova D, Jansen BJ, Nierkens S, et al. Platinum-based drugs disrupt STAT6-mediated suppression of immune responses against cancer in humans and mice. J Clin Invest (2011) 121:3100-8. doi:10.1172/JCI43656

75. Rosenberg SA, Yang JC, Schwartzentruber DJ, Hwu P, Marincola FM, Topalian SL, et al. Immunologic and therapeutic evaluation of a synthetic peptide vaccine for the treatment of patients with metastatic melanoma. Nat Med (1998) 4:321-7. doi:10.1038/nm0398-321

76. Speiser DE, Baumgaertner P, Voelter V, Devevre E, Barbey C, Rufer N, et al. Unmodified self antigen triggers human CD8 T cells with stronger tumor reactivity than altered antigen. Proc Natl Acad Sci U S A (2008) 105:3849-54. doi:10.1073/pnas.0800080105

77. Quakkelaar ED, Melief CJ. Experience with synthetic vaccines for cancer and persistent virus infections in nonhuman primates and patients. Adv Immunol (2012) 114:77-106. doi:10.1016/B978-0-12-396548-6.00004-4

78. Janssen EM, Droin NM, Lemmens EE, Pinkoski MJ, Bensinger SJ, Ehst $\mathrm{BD}$, et al. CD4+ T-cell help controls CD8+ T-cell memory via TRAILmediated activation-induced cell death. Nature (2005) 434:88-93. doi:10.1038/ nature03337

79. Filipazzi P, Pilla L, Mariani L, Patuzzo R, Castelli C, Camisaschi C, et al. Limited induction of tumor cross-reactive $\mathrm{T}$ cells without a measurable clinical benefit in early melanoma patients vaccinated with human leukocyte antigen class I-modified peptides. Clin Cancer Res (2012) 18:6485-96. doi:10.1158/1078-0432.CCR-12-1516

80. Leffers N, Lambeck AJ, Gooden MJ, Hoogeboom BN, Wolf R, Hamming IE, et al. Immunization with a P53 synthetic long peptide vaccine induces P53specific immune responses in ovarian cancer patients, a phase II trial. Int J Cancer (2009) 125:2104-13. doi:10.1002/ijc.24597

81. Speetjens FM, Kuppen PJ, Welters MJ, Essahsah F, Voet van den Brink AM, Lantrua MG, et al. Induction of p53-specific immunity by a p53 synthetic long peptide vaccine in patients treated for metastatic colorectal cancer. Clin Cancer Res (2009) 15:1086-95. doi:10.1158/1078-0432.CCR-08-2227

82. Walter S, Weinschenk T, Stenzl A, Zdrojowy R, Pluzanska A, Szczylik C, et al. Multipeptide immune response to cancer vaccine IMA901 after single-dose 
cyclophosphamide associates with longer patient survival. Nat Med (2012) 18:1254-61. doi:10.1038/nm.2883

83. Palucka K, Banchereau J. Dendritic-cell-based therapeutic cancer vaccines. Immunity (2013) 39:38-48. doi:10.1016/j.immuni.2013.07.004

84. Kruit WH, Suciu S, Dreno B, Mortier L, Robert C, Chiarion-Sileni V, et al. Selection of immunostimulant AS15 for active immunization with MAGE-A3 protein: results of a randomized phase II study of the European Organisation for Research and Treatment of Cancer Melanoma Group in Metastatic Melanoma. J Clin Oncol (2013) 31:2413-20. doi:10.1200/JCO.2012.43.7111

85. Dubensky TW Jr, Reed SG. Adjuvants for cancer vaccines. Semin Immunol (2010) 22:155-61. doi:10.1016/j.smim.2010.04.007

86. Ng L, Heck W, Lavsa S, Crowther D, Atkinson B, Xiao L, et al. The lack of predictors for rapid progression in prostate cancer patients receiving sipuleucel-T. Cancers (Basel) (2013) 5:511-8. doi:10.3390/cancers5020511

87. Kantoff PW, Higano CS, Shore ND, Berger ER, Small EJ, Penson DF, et al. Sipuleucel-T immunotherapy for castration-resistant prostate cancer. N Engl J Med (2010) 363:411-22. doi:10.1056/NEJMoa1001294

88. Galluzzi L, Senovilla L, Vacchelli E, Eggermont A, Fridman WH, Galon J, et al. Trial watch: dendritic cell-based interventions for cancer therapy. Oncoimmunology (2012) 1:1111-34. doi:10.4161/onci.21494

89. Bugaut H, Bruchard M, Berger H, Derangere V, Odoul L, Euvrard R, et al. Bleomycin exerts ambivalent antitumor immune effect by triggering both immunogenic cell death and proliferation of regulatory T cells. PLoS One (2013) 8:e65181. doi:10.1371/journal.pone.0065181

90. Nieuwland R, Sturk A. Why do cells release vesicles? Thromb Res (2010) 125(Suppl 1):S49-51. doi:10.1016/j.thromres.2010.01.037

91. Ludwig A-K, Giebel B. Exosomes: small vesicles participating in intercellular communication. Int J Biochem Cell Biol (2012) 44:11-5. doi:10.1016/j.biocel. 2011.10.005

92. Harding C, Heuser J, Stahl P. Receptor-mediated endocytosis of transferrin and recycling of the transferrin receptor in rat reticulocytes. J Cell Biol (1983) 97:329-39. doi:10.1083/jcb.97.2.329

93. Pan BT, Teng K, Wu C, Adam M, Johnstone RM. Electron microscopic evidence for externalization of the transferrin receptor in vesicular form in sheep reticulocytes. J Cell Biol (1985) 101:942-8. doi:10.1083/jcb.101.3.942

94. Ramakrishnaiah V, Thumann C, Fofana I, Habersetzer F, Pan Q, de Ruiter PE, et al. Exosome-mediated transmission of hepatitis $\mathrm{C}$ virus between human hepatoma Huh7.5 cells. Proc Natl Acad Sci U S A (2013) 110:13109-13. doi:10.1073/pnas.1221899110

95. Admyre C, Johansson SM, Qazi KR, Filen JJ, Lahesmaa R, Norman M, et al. Exosomes with immune modulatory features are present in human breast milk. J Immunol (2007) 179:1969-78.

96. Ma XJ, Dahiya S, Richardson E, Erlander M, Sgroi DC. Gene expression profiling of the tumor microenvironment during breast cancer progression. Breast Cancer Res (2009) 11:R7. doi:10.1186/bcr2222

97. van Doormaal FF, Kleinjan A, Di Nisio M, Buller HR, Nieuwland R. Cell-derived microvesicles and cancer. Neth J Med (2009) 67:266-73.

98. Lasser C, Alikhani VS, Ekstrom K, Eldh M, Paredes PT, Bossios A, et al. Human saliva, plasma and breast milk exosomes contain RNA: uptake by macrophages. J Transl Med (2011) 9:9. doi:10.1186/1479-5876-9-9

99. Yu S, Liu C, Su K, Wang J, Liu Y, Zhang L, et al. Tumor exosomes inhibit differentiation of bone marrow dendritic cells. J Immunol (2007) 178:6867-75.

100. Ma B, Jiang H, Jia J, Di L, Song G, Yu J, et al. Murine bone marrow stromal cells pulsed with homologous tumor-derived exosomes inhibit proliferation of liver cancer cells. Clin Transl Oncol (2012) 14:764-73. doi:10.1007/s12094012-0860-9

101. Andre F, Schartz NE, Movassagh M, Flament C, Pautier P, Morice P, et al. Malignant effusions and immunogenic tumour-derived exosomes. Lancet (2002) 360:295-305. doi:10.1016/S0140-6736(02)09552-1

102. Lynch S, Santos SG, Campbell EC, Nimmo AM, Botting C, Prescott A, et al. Novel MHC class I structures on exosomes. J Immunol (2009) 183:1884-91. doi:10.4049/jimmunol.0900798

103. Chiang CL, Kandalaft LE, Coukos G. Adjuvants for enhancing the immunogenicity of whole tumor cell vaccines. Int Rev Immunol (2011) 30:150-82. doi:10.3109/08830185.2011.572210

104. Petersen SH, Odintsova E, Haigh TA, Rickinson AB, Taylor GS, Berditchevski F. The role of tetraspanin CD63 in antigen presentation via MHC class II. Eur J Immunol (2011) 41:2556-61. doi:10.1002/eji.201141438
105. Zumaquero E, Munoz P, Cobo M, Lucena G, Pavon EJ, Martin A, et al. Exosomes from human lymphoblastoid B cells express enzymatically active CD38 that is associated with signaling complexes containing CD81, Hsc-70 and Lyn. Exp Cell Res (2010) 316:2692-706. doi:10.1016/j.yexcr.2010.05.032

106. Fan W, Tian XD, Huang E, Zhang JJ. Exosomes from CIITA-transfected CT26 cells enhance anti-tumor effects. Asian Pac J Cancer Prev (2013) 14:987-91. doi:10.7314/APJCP.2013.14.2.987

107. Zitvogel L, Regnault A, Lozier A, Wolfers J, Flament C, Tenza D, et al. Eradication of established murine tumors using a novel cell-free vaccine: dendritic cell-derived exosomes. Nat Med (1998) 4:594-600. doi:10.1038/nm0598594

108. Segura E, Nicco C, Lombard B, Veron P, Raposo G, Batteux F, et al. ICAM-1 on exosomes from mature dendritic cells is critical for efficient naive T-cell priming. Blood (2005) 106:216-23. doi:10.1182/blood-2005-01-0220

109. Segura E, Amigorena S, Thery C. Mature dendritic cells secrete exosomes with strong ability to induce antigen-specific effector immune responses. Blood Cells Mol Dis (2005) 35:89-93. doi:10.1016/j.bcmd.2005.05.003

110. Qazi KR, Gehrmann U, Domange Jordo E, Karlsson MC, Gabrielsson S. Antigen-loaded exosomes alone induce Th1-type memory through a B-celldependent mechanism. Blood (2009) 113:2673-83. doi:10.1182/blood-200804- 153536

111. Gabriel K, Ingram A, Austin R, Kapoor A, Tang D, Majeed F, et al. Regulation of the tumor suppressor PTEN through exosomes: a diagnostic potential for prostate cancer. PLoS One (2013) 8:e70047. doi:10.1371/journal.pone.0070047

112. Iero M, Valenti R, Huber V, Filipazzi P, Parmiani G, Fais S, et al. Tumour-released exosomes and their implications in cancer immunity. Cell Death Differ (2008) 15:80-8. doi:10.1038/sj.cdd.4402237

113. Chalmin F, Ladoire S, Mignot G, Vincent J, Bruchard M, Remy-Martin JP, et al. Membrane-associated Hsp72 from tumor-derived exosomes mediates STAT3dependent immunosuppressive function of mouse and human myeloidderived suppressor cells. JClin Invest (2010) 120:457-71. doi:10.1172/JCI40483

114. Yang C, Robbins PD. Immunosuppressive exosomes: a new approach for treating arthritis. Int J Rheumatol (2012) 2012:573528. doi:10.1155/2012/573528

115. Gastpar R, Gehrmann M, Bausero MA, Asea A, Gross C, Schroeder JA, et al. Heat shock protein 70 surface-positive tumor exosomes stimulate migratory and cytolytic activity of natural killer cells. Cancer Res (2005) 65:5238-47. doi:10.1158/0008-5472.CAN-04-3804

116. Hosseini-Beheshti E, Pham S, Adomat H, Li N, Tomlinson Guns ES. Exosomes as biomarker enriched microvesicles: characterization of exosomal proteins derived from a panel of prostate cell lines with distinct AR phenotypes. Mol Cell Proteomics (2012) 11:863-85. doi:10.1074/mcp.M111.014845

117. Guo F, Chang CK, Fan HH, Nie XX, Ren YN, Liu YY, et al. Antitumour effects of exosomes in combination with cyclophosphamide and polyinosinic-polycytidylic acid. J Int Med Res (2008) 36:1342-53. doi:10.1177/ 147323000803600623

118. Taieb J, Chaput N, Schartz N, Roux S, Novault S, Menard C, et al. Chemoimmunotherapy of tumors: cyclophosphamide synergizes with exosome based vaccines. J Immunol (2006) 176:2722-9.

119. Gehrmann U, Hiltbrunner S, Georgoudaki AM, Karlsson MC, Naslund TI, Gabrielsson S. Synergistic induction of adaptive antitumor immunity by codelivery of antigen with alpha-galactosylceramide on exosomes. Cancer Res (2013) 73:3865-76. doi:10.1158/0008-5472.CAN-12-3918

120. Chaput N, Flament C, Viaud S, Taieb J, Roux S, Spatz A, et al. Dendritic cell derived-exosomes: biology and clinical implementations. J Leukoc Biol (2006) 80:471-8. doi:10.1189/jlb.0206094

121. Hao S, Bai O, Yuan J, Qureshi M, Xiang J. Dendritic cell-derived exosomes stimulate stronger CD8+ CTL responses and antitumor immunity than tumor cell-derived exosomes. Cell Mol Immunol (2006) 3:205-11.

122. Munich S, Sobo-Vujanovic A, Buchser WJ, Beer-Stolz D, Vujanovic NL. Dendritic cell exosomes directly kill tumor cells and activate natural killer cells via TNF superfamily ligands. Oncoimmunology (2012) 1:1074-83. doi:10.4161/ onci.20897

123. Viaud S, Terme M, Flament C, Taieb J, Andre F, Novault S, et al. Dendritic cell-derived exosomes promote natural killer cell activation and proliferation: a role for NKG2D ligands and IL-15Ralpha. PLoS One (2009) 4:e4942. doi:10.1371/journal.pone.0004942

124. Zeelenberg IS, Ostrowski M, Krumeich S, Bobrie A, Jancic C, Boissonnas A, et al. Targeting tumor antigens to secreted membrane vesicles in vivo 
induces efficient antitumor immune responses. Cancer Res (2008) 68:1228-35. doi:10.1158/0008-5472.CAN-07-3163

125. Schneider T, Hoffmann H, Dienemann H, Schnabel PA, Enk AH, Ring S, et al. Non-small cell lung cancer induces an immunosuppressive phenotype of dendritic cells in tumor microenvironment by upregulating B7-H3. J Thorac Oncol (2011) 6:1162-8. doi:10.1097/JTO.0b013e31821c421d

126. Naslund TI, Gehrmann U, Qazi KR, Karlsson MC, Gabrielsson S. Dendritic cell-derived exosomes need to activate both $\mathrm{T}$ and $\mathrm{B}$ cells to induce antitumor immunity. J Immunol (2013) 190:2712-9. doi:10.4049/jimmunol. 1203082

127. Nolte-'t Hoen EN, Buschow SI, Anderton SM, Stoorvogel W, Wauben MH. Activated T cells recruit exosomes secreted by dendritic cells via LFA-1. Blood (2009) 113:1977-81. doi:10.1182/blood-2008-08-174094

128. Subra C, Laulagnier K, Perret B, Record M. Exosome lipidomics unravels lipid sorting at the level of multivesicular bodies. Biochimie (2007) 89:205-12. doi:10.1016/j.biochi.2006.10.014

129. Perrin-Cocon L, Agaugue S, Coutant F, Saint-Mezard P, Guironnet-Paquet A, Nicolas JF, et al. Lysophosphatidylcholine is a natural adjuvant that initiates cellular immune responses. Vaccine (2006) 24:1254-63. doi:10.1016/j.vaccine. 2005.09.036

130. Sokolova V, Ludwig AK, Hornung S, Rotan O, Horn PA, Epple M, et al. Characterisation of exosomes derived from human cells by nanoparticle tracking analysis and scanning electron microscopy. Colloids Surf B Biointerfaces (2011) 87:146-50. doi:10.1016/j.colsurfb.2011.05.013

131. Admyre C, Grunewald J, Thyberg J, Gripenback S, Tornling G, Eklund A, et al. Exosomes with major histocompatibility complex class II and co-stimulatory molecules are present in human BAL fluid. Eur Respir J (2003) 22:578-83. doi:10.1183/09031936.03.00041703

132. Obeid M, Tesniere A, Ghiringhelli F, Fimia GM, Apetoh L, Perfettini JL, et al. Calreticulin exposure dictates the immunogenicity of cancer cell death. Nat Med (2007) 13:54-61. doi:10.1038/nm1523

133. Zheng J, Liu Q, Yang J, Ren Q, Cao W, Yu Z, et al. Co-culture of apoptotic breast cancer cells with immature dendritic cells: a novel approach for DCbased vaccination in breast cancer. Braz J Med Biol Res (2012) 45:510-5. doi:10.1590/S0100-879X2012007500061
134. Ghiringhelli F, Apetoh L, Tesniere A, Aymeric L, Ma Y, Ortiz C, et al. Activation of the NLRP3 inflammasome in dendritic cells induces IL-1betadependent adaptive immunity against tumors. Nat Med (2009) 15:1170-8. doi:10.1038/nm.2028

135. Cirone M, Di Renzo L, Lotti LV, Conte V, Trivedi P, Santarelli R, et al. Primary effusion lymphoma cell death induced by bortezomib and AG 490 activates dendritic cells through CD91. PLoS One (2012) 7:e31732. doi:10.1371/journal. pone. 0031732

136. Demaria S, Santori FR, Ng B, Liebes L, Formenti SC, Vukmanovic S. Select forms of tumor cell apoptosis induce dendritic cell maturation. J Leukoc Biol (2005) 77:361-8. doi:10.1189/jlb.0804478

137. Wen CC, Chen HM, Chen SS, Huang LT, Chang WT, Wei WC, et al. Specific microtubule-depolymerizing agents augment efficacy of dendritic cell-based cancer vaccines. J Biomed Sci (2011) 18:44. doi:10.1186/1423-0127-18-44

138. Donnelly OG, Errington-Mais F, Steele L, Hadac E, Jennings V, Scott K, et al. Measles virus causes immunogenic cell death in human melanoma. Gene Ther (2013) 20(1):7-15. doi:10.1038/gt.2011.205

Conflict of Interest Statement: The authors declare that the research was conducted in the absence of any commercial or financial relationships that could be construed as a potential conflict of interest.

Received: 30 October 2013; accepted: 23 November 2013; published online: 11 December 2013.

Citation: Dudek AM, Martin S, Garg AD and Agostinis P (2013) Immature, semimature, and fully mature dendritic cells: toward a DC-cancer cells interface that augments anticancer immunity. Front. Immunol. 4:438. doi: 10.3389/fimmu.2013.00438 This article was submitted to Tumor Immunity, a section of the journal Frontiers in Immunology.

Copyright $\odot 2013$ Dudek, Martin, Garg and Agostinis. This is an open-access article distributed under the terms of the Creative Commons Attribution License (CC BY). The use, distribution or reproduction in other forums is permitted, provided the original author(s) or licensor are credited and that the original publication in this journal is cited, in accordance with accepted academic practice. No use, distribution or reproduction is permitted which does not comply with these terms. 